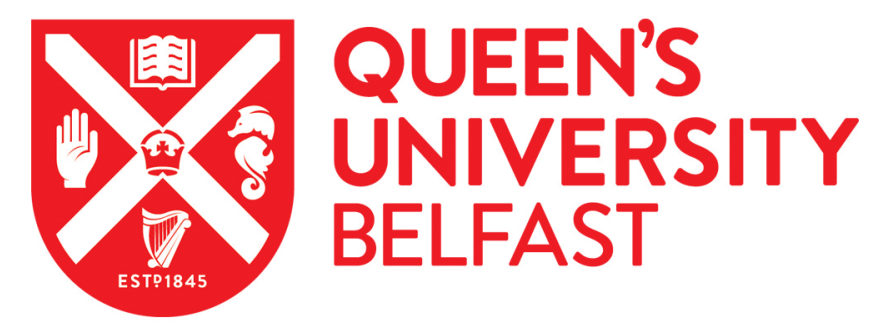

\title{
Making charity effectiveness transparent: building a stakeholder- focused framework of reporting
}

Hyndman, N., \& McConville, D. (2018). Making charity effectiveness transparent: building a stakeholder-focused framework of reporting. Financial Accountability \& Management, 34(2), 133-147.

https://doi.org/10.1111/faam.12148

\section{Published in:}

Financial Accountability \& Management

\section{Document Version:}

Peer reviewed version

\section{Queen's University Belfast - Research Portal:}

Link to publication record in Queen's University Belfast Research Portal

\section{Publisher rights}

(C) 2016 John Wiley \& Sons

This is the peer reviewed version of the following article: which has been published in final form at [Link to final article using the DOI]. This article may be used for non-commercial purposes in accordance with Wiley Terms and Conditions for Self-Archiving

\section{General rights}

Copyright for the publications made accessible via the Queen's University Belfast Research Portal is retained by the author(s) and / or other copyright owners and it is a condition of accessing these publications that users recognise and abide by the legal requirements associated with these rights.

Take down policy

The Research Portal is Queen's institutional repository that provides access to Queen's research output. Every effort has been made to ensure that content in the Research Portal does not infringe any person's rights, or applicable UK laws. If you discover content in the Research Portal that you believe breaches copyright or violates any law, please contact openaccess@qub.ac.uk. 


\title{
MAKING CHARITY EFFECTIVENESS TRANSPARENT: BUILDING A STAKEHOLDER-FOCUSED FRAMEWORK OF REPORTING
}

\author{
Noel Hyndman \\ Queen's University Management School, Riddle Hall, 185 StranmillisRoad,Belfast, UK, \\ BT95DU, n.hyndman@qub.ac.uk \\ Danielle McConville \\ Queen's University Management School, Riddle Hall, 185 StranmillisRoad,Belfast, UK, \\ BT95DU, +44 (0) 289097 4491, d.mcconville@qub.ac.uk
}

\begin{abstract}
Effectiveness in achieving mission is fundamental to evaluating charity performance, and is of central concern to stakeholders who fund, regulate and otherwise engage with such organisations. Exploring the meaning of transparency in the context of stakeholder engagement, and utilising previous research and authoritative sector discussion, this paper develops a novel framework of transparent, stakeholder-focused effectiveness reporting. It is contended that such reporting can assist the charity sector in discharging accountability, gaining legitimacy, and in sharpening mission-centred managerial decision making. Then applying this to UK charities' publicly-available communications, it highlights significant challenges and weaknesses in current effectiveness reporting.
\end{abstract}

\section{Keywords}

Charity, Effectiveness, Not-for-profit, Stakeholder, Transparency 


\section{INTRODUCTION}

In the United Kingdom (UK) context, charities are a particular form of not-for-profit organisation (NFPO) defined in law. They are facilitated through various legal and administrative frameworks by, for example, significant tax benefits and (arguably) lighter-touch legal and regulatory frameworks. The UK charity sector comprises over 161,000 registered general charities with an estimated income of $£ 39.2$ billion (National Council for Voluntary Organisations (NCVO), 2014) $)^{\mathrm{i}}$. In common with other NFPOs, charities have a mission unrelated to profit, for example: the relief of poverty, or the advancement of education. Recent calls for a conceptual framework for NFPOs (Ryan et al., 2014) emphasised the need to recognise this distinctive focus and to provide information on organisational mission and success in achieving that mission. An important aspect of this is the measurement and reporting of effectiveness: measuring what has been achieved and comparing this to mission-based objectives and targets. Charities in particular, and NFPOs in general, have been increasingly called upon to be more transparent about their effectiveness, especially in the context of the increasing use of NFPOs to deliver services previously provided by the public sector (Ryan et al., 2014). Such calls have been particularly observed with respect to the UK charity sector from central government (HM Treasury, 2014), sector interest groups (Inspiring Impact, 2013) and regulators (Charity Commission, 2004).

Calls for transparent reporting on effectiveness often highlight its potential usefulness to a range of internal and external stakeholders, including large funders, charity managers and beneficiaries (Benjamin, 2012; Carnochan et al., 2014). The argument is developed in this paper that transparency (and perhaps ultimately accountability) in respect of effectiveness is an important part of an organisation's stakeholder engagement (Freeman, 1984; Donaldson and Preston, 1995). Moreover, it is contended that appropriate transparency can help cement ethical values, legitimise organisations in the eyes of their stakeholders and provide a basis for the continuing health and growth of the sector (Hyndman and McConville, 2016). However, identifying what constitutes transparency in relation to effectiveness is difficult and, arguably, under-researched. Accordingly, the research objectives of this paper are: to develop, utilising previous research and authoritative sector discussion, a stakeholder-focused framework of transparent reporting on effectiveness; and to use this developed framework to explore UK charities' transparency on effectiveness.

This paper continues as follows. The next section addresses transparency with respect to effectiveness from a stakeholder perspective: defining transparency and effectiveness, clarifying the importance and challenges of reporting on effectiveness in a transparent manner, and 
discussing existing evidence. In the methodology section, a framework is developed as a basis for content analysis of effectiveness disclosures. Subsequently, using the developed framework and focusing on the top 100 UK charities' publicly available communications, findings are presented on the extent and manner of reporting on effectiveness. Finally, conclusions are drawn on the sample charities' transparency and responsiveness to suggested stakeholder needs.

Overall, the paper provides a contribution to the ongoing debate on how charity reporting could, and perhaps should, develop by constructing a novel framework to facilitate more stakeholder-focused and transparent reporting in, arguably, the most important aspect of a charity's performance. In doing so, it presents a distinctive tool that, it is contended, can support the charity sector in discharging accountability, gaining legitimacy and in sharpening missionfocused managerial decision making. In addition, the paper, in applying the developed framework to a sample of large UK charities, highlights significant challenges and weaknesses in current effectiveness reporting. Such can inform future decisions of those charged with steering, regulating and encouraging the sector towards greater transparency in reporting practices.

\section{STAKEHOLDERS, TRANSPARENCY AND EFFECTIVENESS}

\section{A stakeholder perspective on transparency}

Transparency has been defined in many ways and in a variety of contexts. With respect to governance and accountability, it is often seen as enabling stakeholders to gain information about an organisation, including: its processes and performance; its structures; and information regarding who gains from, or pays for, the organisation's activities (Heald, 2006a; Etzioni, 2010). It is often associated with (but not fully synonymous with) openness and disclosure (Heald, 2006a), with mere disclosure suggested as insufficient: 'it can achieve rather little unless the material disseminated is made accessible to and assessable by relevant audiences, and actually reaches those audiences' (O’Neill, 2006, p.84). Transparency has been suggested as desirable in and of itself (an intrinsic value) and as a means to other primary goals (an instrumental value) including accountability, legitimacy, effectiveness and fairness (Heald, 2006b). However, it has been suggested that transparency may not be beneficial in all contexts, with Heald (2006b, p.71) analogising transparency as either sunlight or torch: 'when sunlight becomes searchlight it can be uncomfortable and when it becomes torch it may be destructive'.

In charities, transparency and accountability have been increasingly discussed as owed to stakeholders, with authors often stressing engagement with a broad range of stakeholders as essential in discharging accountability (Ebrahim, 2003; Dhanani and Connolly, 2012). The Charity Commission (the regulator in England and Wales) defines accountability as a charity's 
response to the legitimate information needs of its stakeholders (Charity Commission, 2004). Stakeholders have been defined as 'any group or individual who can affect or is affected by the achievement of the organisation's objectives' (Freeman, 1984, p.46). In a charity context, stakeholders might include: large funders, individual donors, beneficiaries, government, regulators, the general public, charity employees and sector interest groups. As argued by Freeman (1984) and Donaldson and Preston (1995), engagement with such groups/individuals can help an organisation fulfil its objectives by aligning its goals with those of its key stakeholders.

Ebrahim (2003) has drawn parallels between stakeholder engagement and the ethical values, cultures and activities of charities. Charity managers may be particularly motivated to engage with stakeholders, with such engagement likely to lead to a 'warm glow' on the part of charity managers (Brown and Caughlin, 2009). Hyndman and McConville (2016) suggested that this moral imperative may be combined with charity managers' desire to legitimise the organisation in the eyes of its stakeholders. Used in this way, legitimacy can be viewed as the extent to which an organisation's actions align with social norms and expectations (particularly key stakeholders' expectations). Convincing stakeholders of legitimacy is particularly important in a sector which relies on public trust to sustain and develop its activities (Saxton et al., 2012). Such moral and legitimation motivations are not mutually exclusive and are likely to be experienced and acted upon differently by heterogeneous charity managers. Where charity managers are motivated to engage with their stakeholders, transparency may be an important aspect of this: reporting useful, good-quality, understandable information as a basis for meaningful engagement (and perhaps ultimately accountability). This has been suggested as beneficial to both stakeholders and the organisation: encouraging further funding, decreasing monitoring costs and delivering better societal outcomes (Saxton et al., 2012).

\section{The importance of transparency on effectiveness}

From a stakeholder perspective, transparency regarding effectiveness may be particularly important. Most external stakeholders engage with charities for reasons linked to the mission of the charity and its activities (and achievements) in support of that mission. By discussing and reporting on effectiveness, charities can focus on matters that are at the core of many stakeholders' interest and concern (whether, for example, such stakeholders provide funds, receive benefits or are tasked with promoting good governance). Effectiveness in this study is defined as the comparison of outputs and/or outcomes from charitable activity to specific measurable targets related to the mission of the organisation. Outputs are defined as the 
immediate or direct services (or products) provided by a charity, for example, the number of children fed, or cancer research projects completed. Outcomes ${ }^{\text {ii }}$ relate to the effect of an organisation's activities on individuals (such as an increase in employability, termed an individual outcome in this study) or society (for example: a reduction in youth reoffending, termed a societal outcome). Reporting of specific measures is not required by the Statement of Recommended Practice (SORP: Charity Commission and Office of the Scottish Charity Regulator (OSCR), 2014) iii. However, both the SORP $^{\text {iv }}$ and sector guidance (NCVO, 2011) have encouraged charities to report a suite of output, outcome and effectiveness measures, both to increase effectiveness and to highlight this more clearly to external stakeholders.

Research in this area suggests that external stakeholders are interested in effectivenessrelated information, with information on outcomes and outcome-based measures of effectiveness argued to be particularly important. Individual donors are shown to be much more interested in mission, goal, programme and outcome information than in traditional financial information (Connolly and Hyndman, 2013a) and draw on such when making donation decisions (McDowell et al.,, 2013). Surveys of the general public indicate widely held views that charities must demonstrate the benefits which they generate (Populus, 2016). Moreover, large funders (especially those commissioning public services) increasingly demand outcome information in order to target resources at proven solutions to social problems (Lumley et al., 2011; Connolly and Hyndman, 2013a). Among these, the UK government ${ }^{\mathrm{v}}$ has progressively linked payment for services to outcomes and often requires detailed, quantified reporting of such through various channels (HM Treasury, 2014). Disclosure of outcomes has been particularly suggested as having potential to strengthen both upward accountability to donors and funders and downward accountability to beneficiaries (Benjamin, 2012; Connolly and Hyndman, 2013b).

\section{Challenges to transparency on effectiveness}

Measuring and reporting on effectiveness may be especially difficult due to problems in determining appropriate outputs and outcomes. Taking the example of human services organisations, Carnochan et al. (2014) highlighted challenges relating to the complexity of client progress (for example, towards addiction recovery or employability) and in aggregating such complex data for the organisation as a whole. Difficulties also exist in: developing appropriate measures given a lack of guidance and limited skills in the sector (Lumley et al., 2011); collecting relevant information in a cost-effective way (Hedley et al., 2010); and establishing processes and systems to capture such information in an accurate and objective manner (Carnochan et al., 2014). Other problems include isolating the effect of a charity's work from the work of other 
organisations (Nevill and Lumley, 2011) and measuring performance which is identifiable only over the long term (Hedley et al., 2010).

Furthermore, managers may be reluctant to disclose information that they feel might damage their charity's legitimacy, for example information that could be misunderstood or seen as failure (Ebrahim, 2003). This may be particularly the case following a small number of widely reported scandals relating to charities and continuing concerns relating to executive salaries and use of funds in the sector (Murray et al., 2016; Populus, 2016). Given the media interest in such issues, and the danger of such being 'spun' for impact, charities may be particularly wary of transparently providing information or being innovative in reporting. These issues may be magnified for charities engaged in certain types of activity which attracts less public support (such as addiction services), or lobbying charities that have opposed government policies.

Moreover, given that charities have different missions and internal structures, and, as a consequence, undertake different activities and pursue different results, measures of outputs, outcomes and effectiveness are unlikely to be easily standardised or compared. This will be particularly the case where charities operate in vastly different spheres of the sector (such as medical research charities and animal welfare charities). In such cases, transparency on measures - beyond mere disclosure - becomes more important. Charities may need to explain carefully and contextualise the measures they provide in order to make their disclosures meaningful and accessible to relevant stakeholders (echoing O’Neill, 2006). In addition, information that allows stakeholders to assess or evaluate what is provided will be useful to inform their decision-making processes. These themes are further developed in the framework (Table 1).

\section{Existing evidence on transparency on effectiveness}

Despite the importance of disclosing effectiveness information (potentially the ultimate expression of mission-centred performance), and perhaps reflecting its challenges, previous empirical research has identified extremely low levels of reporting by UK charities. For example, Connolly and Dhanani (2009) identified measures of effectiveness in only four per cent of Trustees' Annual Reports (TARs). However, with respect to the reporting of outputs and outcomes (key elements of a performance production model), research has suggested more, and at times increasing, disclosure. For instance, in the case of output disclosures, over a period in excess of 20 years this has increased from a minority activity (29 per cent of sample charities' TARs: Hyndman, 1990) to a situation where the vast majority of charities now provide some output information (85 per cent of sample charities' TARs: Connolly and Hyndman, 2013b). 
Reporting of outcomes is more varied, with Breckell et al. (2011) identifying that most charities provided at least some information on individual outcomes, compared to only eight per cent providing information on societal outcomes.

Much of the research in this area has concentrated on the degree of reporting (with researchers often arguing that low levels of reporting is indicative of weak accountability), while little has considered the manner or transparency of these disclosures. Connolly and Dhanani (2009), in studies focused on the degree of reporting of performance information, identified that no charities in their sample accompanied reported measures with comparatives or explanations, making it difficult for users to appreciate and contextualise disclosures. In a similar vein, a number of authors (Hedley et al., 2010; Breckell et al., 2011) have raised concerns about the quality and manner of performance reporting by charities, arguing that mere disclosure is not sufficient to ensure meaningful communication and engagement.

\section{METHODOLOGY}

In response to the first research objective of this paper, a stakeholder-focused framework of transparent reporting on effectiveness was constructed (shown as Table 1) ${ }^{\mathrm{vi}}$. This framework was developed utilising past academic research, relevant authoritative guidance and sector discussion, and guided by O'Neill's (2006) suggestion that, for transparency, disclosures should meet the information needs of stakeholders and be accessible to and assessable by those stakeholders.

Charities are encouraged to provide a suite of measures that demonstrate effectiveness (Charity Commission and OSCR, 2014) and Table 1 defines five such measures: output, individual outcome and societal outcome measures (three key elements of a performance production model); and output-based and outcome-based effectiveness measures (relating performance to pre-set targets). In terms of assessability, explanations, comparatives and links to mission can contextualise what is reported (NCVO, 2011). Format may also be important in making measures accessible to relevant stakeholders (O’Neill, 2006; Inspiring Impact, 2013), particularly where quantitative and qualitative data is presented together: Hedley et al. (2010) advocating 'no numbers without stories, no stories without numbers' (p.9). Table 1 indicates possible formats. Helping stakeholders to assess what is provided, Table 1 suggests accompanying measures with information that indicates: reliability (useful internally to drive improvement - Inspiring Impact, 2013 - and externally to create 'an image of integrity and transparency' - Hedley et al., 2010, p.11); causality (acknowledged as difficult but important Puttick and Ludlow, 2012; Carnochan et al., 2014); and stakeholder involvement (as a means to guard against mission drift and ensure outcomes assessment is robust and unbiased - NCVO, 
2011; Inspiring Impact, 2013). It is acknowledged that some aspects of the framework may be contestable and more appropriate for some charities than others, and that the framework is likely to evolve as reporting practices develop. ${ }^{\mathrm{vii}}$ Accordingly, the framework is not intended to be prescriptive as to what charities should report, but rather provides a lens through which reporting practice can be viewed.

\section{$<<$ Table 1 here $>>$}

The framework was applied to the major publicly-available communications of the top 100 UK charities. This study focused on these charities as they are economically significant and expected to be at the forefront of good reporting practice. The top 100 charities (by income) were identified using the Caritas Data Top 500 charities list (Caritas Data, 2011), excluding charities that are entirely funded by endowed funds, trusts or similar sources, and which do not engage directly in charitable activity. ${ }^{\text {viii }}$ This sample deliberately included charities active in a range of functional areas, including overseas aid, disability, health and poverty. Annual income of these charities ranged from $£ 40$ million to almost $£ 600$ million (with an average of $£^{110}$ million). ${ }^{\mathrm{ix}}$

The data analysed included TARs, Annual Reviews and websites. Large charities in the $\mathrm{UK}$ are required to prepare a TAR which is subject to the SORP, Companies Act requirements (for charities registered as companies) and review (but not audit) by the external auditor. TARs are seen as the most important publicly-available communication by a range of stakeholders (Connolly and Hyndman, 2013b). Annual Reviews ${ }^{\mathrm{x}}$ were also included as charities provide additional accountability information in these documents (Charity Commission, 2004), often less formally and with a higher proportion of stories, photographs and diagrams. These documents (which are not produced by all charities) are not subject to the requirements of the SORP, Companies Act or auditor review, but are perceived as engaging with a wider audience (including beneficiaries and individual donors: Connolly and Hyndman, 2013b). A search was carried out for Annual Reviews on websites and by contacting charities (in total, 63 were obtained and analysed).

Website disclosures (a now frequently-used communication seldom examined in previous studies of charity reporting) were also included in the analysis. Website searches were carried out over a two-month period concurrent with the collection of TARs and Annual Reviews (in an attempt to approximate a similar timeframe of reporting across all media). For each website, two searches were carried out for relevant information, limited to 10 minutes in duration and using 
site search engines, signposting and hyperlinks internal to the charity's website. Where the TAR and Annual Review were available on the website, these were excluded and analysed separately. In total, 99 websites were reviewed (one charity did not have a website).

Content analysis was then applied to all the material gathered, categorising and codifying the collected information by reference to a specially-developed checklist of pre-defined categories, in order to identify patterns in that reporting (Krippendorff, 2013). Each sentence, headline, table and diagram was categorised as including framework measures or not. These text units were then coded according to a detailed checklist and rules for analysis. The checklist operationalised the framework presented in Table 1, so that in the analysis a deductive, mechanistic (Beck et al., 2010) approach was taken. This allowed confirmation of whether the framework measures were present (yes/no), and, when present, the number and format of disclosures, and whether comparatives, explanations, diagrams or information indicating links to mission and goals, reliability, causal relationships and stakeholder involvement were present (yes/no). Strategies to maximise reliability included: repeating the coding procedure (Schreier, 2012); developing the categories (Table 1) from well-grounded and relevant literature (Krippendorff, 2013); pilot testing (Schreier, 2012); and on-going revision of the checklist and rules for analysis (Krippendorff, 2013).

\section{FINDINGS}

\section{Increased reporting of all measures since previous studies}

If charities are to be transparent with respect to effectiveness, the disclosure of related measures in their publicly-available communications is important. While charities may report on a range of measures to demonstrate their effectiveness (NCVO, 2011), the developed framework (Table 1) presented and argued for five types of measure that may be useful to stakeholders, relating to outputs, outcomes and effectiveness. Table 2 indicates the proportion of sample charities that reported at least one such measure in: any communication; their TAR (of a population of 100 TARs); Annual Review (of a population of 63 such reports); or website content (of a population of 99 websites). In addition, the table also shows the extent to which at least one of the five framework measures was disclosed in each communication or in any communication.

\section{$<<$ Table 2 here $>>$}


In Table 2, if an output or outcome (individual or societal) was shown with a target, it was counted only once as a measure of effectiveness (output-based or outcome-based); if an output or outcome was shown without a target, it was counted solely as an output or outcome. ${ }^{\mathrm{xi}}$ With respect to output measures, all but one charity reported at least one measure in at least one publicly-available communication. Measures of output were provided in 93 per cent of TARs, 94 per cent of Annual Reviews and 70 per cent of websites (Table 2). Outputs were provided by more charities than any of the other four measures when considering 'any communication' channel. This confirms a continuing inclination, previously identified, towards greater disclosure of such measures over time (Connolly and Hyndman, 2013b).

In respect of individual outcomes, 90 per cent of the sample charities reported at least one measure in their communications, most commonly in the Annual Review (84 per cent, compared to 65 per cent of TARs and 62 per cent of websites, Table 2). In the case of societal outcomes, 64 per cent of charities reported at least one measure, most commonly in their Annual Reviews or TARs (Table 2). These levels of outcome reporting represent a significant increase on the 68 per cent and eight per cent reporting on individual and societal outcomes respectively found earlier by Breckell et al. (2011). That societal outcomes remain less commonly reported than individual outcomes may reflect greater difficulties in measuring societal outcomes (Hedley et al., 2010; Nevill and Lumley, 2011) or charities' awareness of stakeholders' interest in (the possibly easier to report) individual outcomes (Connolly and Hyndman, 2013a). Overall, through time, many more charities are voluntarily reporting on outcomes, and possible reasons for this may include: responses to perceived stakeholder needs; the influence of peer charities' reporting; and improving internal systems to capture and report such data.

In the framework (Table 1), the two measures that, arguably, relate to the ultimate expression of mission-centred performance are output-based effectiveness and outcome-based effectiveness. Levels of reporting of these measures in any communication channel are much lower than those relating to outputs and outcomes (output-based effectiveness 42 per cent; outcome-based effectiveness 26 per cent, Table 2). Moreover, if present, they are commonly reported in the TAR (viewed as the most important communication channel - Connolly and Hyndman, 2013a) and rarely presented on the website. However, relatively, the disclosure of such information has increased significantly over time. For example, Connolly and Dhanani (2009) found only 4 per cent of charities disclosing any effectiveness information. This increase over time may indicate a degree of travelling towards effectiveness reporting, possibly driven by a desire for 'compliance' with the SORP's recommendations on reporting achievements against objectives in the TAR in order to indicate legitimacy. Taken together, Table 2 (final row) also 
shows that all charities in the sample report at least one of these framework measures in at least one communication, with all Annual Reviews, 97 per cent of TARs and 88 per cent of websites containing at least one such measure.

These results, when compared with previous studies, show that the proportion of charities reporting each measure has increased over time. However, significant gaps still remain. For example, the majority of sample charities do not disclose any output-based or outcomebased effectiveness information, and a significant number report no measures of outcomes. One possible reason is that charities are not motivated to report such measures, perhaps because of perceived insufficient stakeholder interest in such disclosures. Conversely, while stakeholder interest (as has been shown in previous studies) may be recognised, disclosure may be hampered by significant challenges. These include resource constraints and difficulties in setting meaningful (particularly outcome) targets and measuring achievements against these (see also Carnochan et al., 2014). In addition, limited reporting of output-based or outcome-based effectiveness measures may also reflect a particular tension for managers concerned that reporting on targets missed will be seen (perhaps simplistically) as failure. In contrast to other measures, where ethical and legitimating motivations may be in alignment, reporting on targets missed, while perhaps morally correct, could threaten legitimacy and damage the organisation (particularly if likely to be seized upon by an unsupportive media).

Table 2 reported proportions of charities providing at least one framework measure in their communications. However, the extent of reporting may also be important, especially given the various spheres of activity with which an individual charity may engage. Table 3 details the extent of reporting of the framework measures (as per Table 1) by communication channel, and details: the number of charities reporting at least one such measure (no.), the total (tot.) measures reported by all reporting charities, the mean value (based on the number of reporting charities) and the maximum (max.) number of measures provided by any charity.

\section{$<<$ Table 3 here $>>$}

As can be seen in Table 3, outputs were the most commonly provided measure across all communications. For example, the mean number of output measures provided in a TAR was 39.37 (52.34 in Annual Reviews). This was much higher than the disclosure of individual outcome measures (mean 8.77 TAR; 18.77 Annual Review) and societal outcomes (mean 5.76 TAR; 13.12 Annual Review). To some extent this might be expected, as outputs have been more reported in previous years (Connolly and Dhanani, 2009) and are viewed as easier to measure 
than outcomes (Hedley et al., 2010). However, it is important to note that, for transparency, more reporting is not necessarily better. Saxton et al. (2012) argued that too much disclosure can result in 'information overload', alienating funders and other stakeholders. Some charities provided enormous numbers of output measures: from Table 3, one charity provided 449 output measures in its Annual Review, and another provided 128 individual outcomes. In these cases, it may be that other measures, such as societal outcomes or effectiveness, are crowded out.

From Tables 2 and 3, it is seen that, in many charities, the reporting of outputs and outcomes is fairly extensive. When comparisons are made over time (utilising earlier research) there is clear evidence of greater disclosure than in earlier periods. This reporting is generally more pervasive and extensive in Annual Reviews than TARs and, with the exception of individual outcomes ${ }^{\mathrm{xii}}$, considerably less so on websites (when TARs and Annual Reviews are excluded). Each of the first three framework measures (output, individual outcome and societal outcome) was more disclosed in charity Annual Reviews than TARs, and, if disclosed, more likely to have greater numbers of disclosures. However, the pattern is different when focusing on measures of effectiveness (arguably, a higher level of performance reporting), with TARs much more frequently used for the disclosure of measures of effectiveness. From a stakeholder theory perspective, given that some stakeholders engage more with some communications than others (Connolly and Hyndman, 2013b), these differences in reporting could be seen as attempts by charity managers to engage with different stakeholder groups and respond to varying information needs.

\section{Few charities provided comparatives or explanations, and formats vary}

In developing the framework (Table 1) features that might improve assessability were suggested, including: the provision of explanations and comparatives (to prior year and target); and the use of a variety of formats (numerical, narrative and case study). Given this, Table 4 shows the total number of framework measures of each type reported in all communications combined, and the proportion of those measures: accompanied by a comparative (to past performance or external benchmark) or an explanation. The table also shows the proportion of reported measures in each format (either numerical, narrative or case-study presentation), which sums to 100 per cent.

\section{$<<$ Table 4 here $>>$}

Table 4 indicates that few charities reporting on outputs, outcomes and effectiveness linked their reported measures to past or external comparatives. Prior-year comparatives were 
rarely provided (maximum of 16 per cent of output-based effectiveness measures; much lower with other measures - Table 4), largely preventing stakeholders from contextualising performance as better or worse than the previous year. This indicates a frequent failure to highlight trends in performance and possibly suggests a lack of consistency and objectivity in reporting over time (Dhanani and Connolly, 2012). In addition, external comparatives were almost never provided (shown as zero per cent in Table 4), suggesting significant difficulties (or reluctance) in comparing the performance of even apparently similar charities. Explanations of measures were also rare, with effectiveness measures most explained ( 28 per cent of outputbased measures of effectiveness; 33 per cent of outcome-based measures of effectiveness Table 4). These explanations usually related to reasons for performance differing from target. Given the complex and organisation-specific nature of many of the measures presented, it is likely that failure to provide comparatives and explanations leads to weak transparency: with assessability remaining low even though disclosure has increased over time (Tables 2/3). Notwithstanding this, comparisons and explanations are more frequently provided than previously (Connolly and Dhanani, 2009); indicating a degree of travel towards more transparent reporting on effectiveness.

With formats suggested as important for both accessibility and assessability (Inspiring Impact, 2013), Table 4 shows many charities providing disclosures in a range of formats. Outputs and output-based measures of effectiveness are more commonly given in numerical terms, while narrative or case-study approaches were more commonly used to describe outcomes. For example, 61 per cent of individual outcomes were presented using a case study (Table 4), perhaps because these reasonably easily produced 'stories' are perceived as attractive to and useful by stakeholders (Connolly and Hyndman, 2013a). However, they may be weak evidence of wider achievements (Hedley et al., 2010). The degree of quantification identified in this research, particularly in respect of outcomes (Table 4) was much greater than in previous studies that identified outcome-related disclosures as entirely narrative (Connolly and Dhanani, 2009). This may represent a response to demands for greater quantification from stakeholders, including the UK government (HM Treasury, 2014). It suggests improvement over time, particularly given claims that quantifying what has been done can create a perception (or even a reality) of greater reliability and transparency (Hedley et al., 2010). Additionally, the range of formats observed within communications may reflect calls to provide both stories and numbers (Hedley et al., 2010) aimed at facilitating both user understanding and user engagement.

Few charities provided information on links to mission, reliability, causal relationships or stakeholder involvement 
Additional information on links to mission, reliability, causal relationships or stakeholder involvement can assist stakeholders in evaluating effectiveness-related information and may be important for transparency, particularly relating to the assessability of provided measures (O’Neill, 2006). Accordingly, the framework (Table 1) presented, explained and argued for 10 elements of information that could be provided with any reported measure. These 10 elements were grouped across four themes: links to overall mission or long-term goals, reliability, causality and stakeholder involvement. For each of the framework measures reported and analysed ${ }^{\text {xiii }}$, further content analysis was used to identify the extent to which additional information relating to these was provided. The findings were combined for each charity across all of their reported measures in all communications so that for each of the 10 elements of additional information it was possible to categorise the percentage of the charity's measures accompanied by that information. These categories ranged from $0 \%$ (no measures were accompanied by this additional information) to 100\% (all measures were accompanied by this additional information). Table 5 then summarises the proportion of charities in each category for each element. For example, from the first line of Table 5, 29 per cent of charities linked none of their output, outcome or effectiveness measures to overall mission or long-term goals, 19 per cent linked one per cent to 20 per cent of such measures to mission or long-term goals, and so on. As all sample charities reported at least one framework measure in at least one communication, all 100 charities are included in Table $5(\mathrm{n}=100)$.

\section{$<<$ Table 5 here $>>$}

Table 5 indicates that the majority ( 71 per cent, Table 5 ) of charities contextualised at least some of their framework measures by linking these to mission or goals. ${ }^{\text {xiv }}$ Given that mission and long-term goals are often framed in terms of outcomes (for example, reducing child poverty) this may be useful in giving a sense of societal impact or effectiveness where specific measures are not provided.

However, information that would allow stakeholders to judge the reliability of measures provided was regularly lacking, a particular issue given that outputs and outcomes are usually measured by the charity itself. The vast majority of the sample charities provided no information that would allow a stakeholder to evaluate the method or source data used (92 and 90 per cent respectively - Table 5). Moreover, most provided no evidence of any external verification of the measures (89 per cent - Table 5), possibly reflecting the expense and difficulties of verification. 
In respect of neutrality, more was reported; 34 per cent of charities provided at least a few 'bad news' items. However, such reporting was usually limited to one or two items of bad news in an overwhelmingly positive report, possibly indicating a degree of tokenism (Dhanani and Connolly, 2012). Overall, these reporting practices may undermine perceptions of credibility or reliability in respect of reported framework measures, possibly threatening perceptions of legitimacy and weakening essential stakeholder support (Hedley et al., 2010).

One of the most difficult aspects of reporting on outcomes (and outcome-based effectiveness) is the establishment of causal relationships between charitable activities and the outcomes identified (Carnochan et al., 2014). As shown in Table 5, most charities provided no information explaining the extent to which activities undertaken had driven the change reported (83 per cent), or what may have happened without the charity's intervention (93 per cent). Some charities attempted to clarify causality by explaining factors, other than their activity, that may have impacted on the outcomes reported: 41 per cent of charities provided this information for at least a few measures (Table 5). Failing to clarify causality may be problematic if it suggests that charities are taking unwarranted credit (Inspiring Impact, 2013), which could threaten the legitimacy of these charities in the eyes of stakeholders.

The framework (Table 1) also argued for involving stakeholders in developing appropriate measures of performance and in monitoring that performance. However, the vast majority of sample charities (96 per cent, Table 5) provided no information indicating that stakeholders had been involved in the design of effectiveness measures. Some (34 per cent Table 5) disclosed some evidence of stakeholder involvement in measuring performance, often by reporting selected results or comments from user-satisfaction surveys. While acknowledging that stakeholder involvement is challenging (particularly when trying to involve beneficiaries), such low levels of reporting indicate a possible lack of robustness in evaluation, or even a danger of disconnect between reporting and mission (often expressed in terms of outcomes for certain stakeholders, particularly beneficiaries) (NCVO, 2011).

\section{CONCLUSIONS}

Transparency with respect to effectiveness has been argued in this paper as a critical aspect of charities' engagement with a range of stakeholders. With effectiveness seen as the ultimate expression of performance in charities, transparency on effectiveness has the potential to improve accountability and legitimacy, and even to increase effectiveness by facilitating better decision making and guarding against mission drift. Having identified a lack of academic research on the transparency of effectiveness reporting (but a plethora of sector guidance), this paper 
developed a novel framework of stakeholder-focused, transparent reporting on effectiveness. Applying this framework to the publicly-available communications of UK charities identified that transparency on effectiveness by these charities is partial and varied, notwithstanding significant differences in practice between charities.

To the extent that comparisons can be made with previous studies (studies that use significantly less comprehensive and less detailed frameworks for data analysis), the findings of this paper suggest a journey of improvement in transparency on effectiveness, with the extent of reporting increasing over time (indicating more accessibility), and, latterly, joined by some limited improvements in the manner of reporting (possibly indicating some increase in assessability). To a degree, these improvements may have been influenced by increased 'messaging' on the importance of transparency and effectiveness (especially relating to outcomes) in recent sector debate. Such messages included published research and the issuance of comments, position papers and guidance from sector interest groups such as Inspiring Impact, New Philanthropy Capital and the NCVO. The Charity Commission has similarly advocated increased reporting both in its guidance and in the SORP. This messaging reflects a broader 'spirit of the age' in reporting: particularly embraced in the public sector (a major funder of charity activity), which has increasingly mandated the use of 'logic' or performance production models and outcome reporting. These encouragements have been widely expressed over many years, and the improved reporting identified in this paper may be a function of both increased awareness of the importance of such information and a 'bedding-in' of related reporting processes and practices in charities.

In this paper, the framework measures have been presented as the most meaningful measures of what a charity exists to do, and their disclosure advocated as a means of signalling success, good practice and legitimacy to a range of stakeholders. On this basis, increased reporting of these measures in publicly-available communications may represent attempts by charity managers to respond to stakeholder needs and (in various ways) secure their continuing support. Evidence in this paper shows that different information (in varying quantities and formats) is provided in different communications, potentially indicating that these communications are being used to engage with particular stakeholders and to respond to their specific needs. Examples include the increased reporting of societal outcomes: of interest to large funders including government, with this reporting increasingly quantitative as often demanded by these stakeholders. A contrasting example is of increased reporting on individual outcomes, highlighted as useful to individual donors and informing their giving decisions. In this case, the format of such reporting often involves the use of case studies or stories likely to engender an 
emotional response. While numbers-based reporting can seem 'cold' in the context of charities, and stories-based reporting alone may fail to give a sense of the scale of activities or their outcomes, combining these approaches (as evidenced in this paper) may usefully respond to the needs of a range of stakeholders and give a more balanced view of effectiveness.

Aside from a degree of improvement over time, largely in terms of the amount of disclosure, comparing the developed framework to publicly-available communications suggested major weaknesses in the transparency of extant effectiveness reporting. This indicates that, in many charities, key information desired by stakeholders, and on which stakeholders rely to make judgements and decisions, is either not available, or not available in a manner with which they can engage and understand. For example, relating to disclosure, many charities failed to provide any information on societal outcomes and effectiveness measures (information identified by previous studies as of high importance to many principal stakeholders). Moreover, this research identified significant issues in the manner of reporting, with measures often lacking comparatives, explanations and information allowing the reader to judge reliability, causality and stakeholder involvement. On this basis it is suggested that, in many cases, even when measures are provided this may be mere disclosure rather than meaningful transparency (Heald, 2006b; O'Neill, 2006) and stakeholder needs, the central focus in the development of the framework, may not be met. Possible reasons for this include difficulties in measurement and lack of resources to devote to data capture and reporting.

Alternatively, exploring these gaps from charity managers' perspectives, these are voluntary disclosures, and information that charity managers may be reluctant to disclose in case it is misinterpreted or misused (perhaps reflecting the potential for transparency to be sunlight, searchlight or torch - Heald, 2006b). In deciding whether to report (and whether to report transparently), charity managers may weigh the possible benefits and costs/risks of such reporting. From a charity perspective, ideally what is provided should be sufficient to inspire stakeholders to engage positively (perhaps leading to donations or volunteering, or confidence/trust in the charity). However, if stakeholders' information needs are insufficiently met in publicly-available communications, more costly direct communications may be used to provide connection (particularly in cases where stakeholders are sufficiently powerful to demand these). Without such positive connection, stakeholders may perceive the organisation as less legitimate (and in need of more focus and control) and less worthy of support and engagement. Such may be detrimental to the health and survival of individual charities, and to the development and growth of the sector as a whole. 
The major contribution of this paper is the development of a novel stakeholder-focused framework of transparent reporting on effectiveness. Arguably, such reporting highlights a paramount aspect of a charity's performance, and is of central interest to a range of stakeholders. By concentrating on stakeholder needs and highlighting the principles of accessibility and assessability of information, it has the potential to facilitate meaningful reporting of critical information, an essential aspect of engagement between charities and their stakeholders. Applying the framework to a sample of large UK charities (as was done in this paper), highlights ongoing weaknesses in transparency on effectiveness; albeit, by comparison with earlier (more limited) studies, a degree of improvement over time is suggested. It is contended that transparent reporting on effectiveness is critical because, without such transparency, charities may struggle to discharge accountability, their legitimacy may be questioned, and they may engage in activities which are less effective or are removed from their mission.

Moreover, improving transparency on effectiveness can support individual charities, and the sector as a whole, in seeking to generate more informed commentary on the sector as a basis for enhancing its legitimacy. This paper also contributes to the broader sector debate on how charity (and NFPO) reporting should develop (Ryan et al., 2014), both by identifying the extent of transparency on effectiveness, and by providing a useful tool that can act as a guide for those seeking to shape and control the development of the sector (be they policy makers, regulators, oversight agencies or sector-wide support organisations). In addition, it may encourage further debate on the meaning and outworking of transparency in relation to charity reporting and, in doing so, encourage sharper reporting and more mission-centred decision making.

A range of further related research is also possible and is to be encouraged. The validation of the developed framework in the field could be achieved by qualitative research engaging with key stakeholders. Such has the potential to refine further the framework suggested, and to identify aspects that may be particularly important (or unimportant) to different spheres of charity (or NFPO) activity. The empirical work that is an aspect of this research focuses solely on large UK charities. Other work considering different sizes of organisation, different organisational forms, or charities engaged with particular causes or means of operation could identify differences in transparency on effectiveness related to these factors; in addition, it might explore whether the elements within the framework need adjusting for these. Finally, further studies, comparing charities (and NFPOs) from different jurisdictions, might facilitate a more international reflection on the issues dealt with in this paper. 


\section{REFERENCES}

Beck, A.C., D. Campbell, and P.J. Shrives (2010), 'Content Analysis in Environmental Reporting Research: Enrichment and Rehearsal of the Method in a British-German Context', The British Accounting Review, Vol. 42, No. 3, pp. 207-222.

Benjamin, L.M. (2012), 'The Potential of Outcome Measurement for Strengthening Nonprofits' Accountability to Beneficiaries', Nonprofit and Voluntary Sector Quarterly, Vol. 42, No. 6, pp. 1224-1244.

Breckell, P., K. Harrison and N. Robert (2011), Impact Reporting in the UK Charity Sector, (www.cfg.org.uk).

Brown, E. and K. Caughlin (2009), 'Donors, Idealogues and Bureaucrats: Government Objectives and the Performance of the Nonprofit Sector', Financial Accountability \& Management, Vol. 25, No. 1, pp. 99-114.

Caritas Data (2011), The Top 500 Charities, (www.charitiesdirect.com) ${ }^{\mathrm{xv}}$.

Carnochan, S., M. Samples, M. Myers and M.J. Austin (2014), 'Performance Measurement Challenges in Nonprofit Human Services Organizations', Nonprofit and Voluntary Sector Quarterly, Vol. 43, No. 6, pp. 1014-1032.

Charity Commission (2004), RS8: Transparency and Accountability, Charity Commission (London).

Charity Commission and Office of the Scottish Charity Regulator (2014), Accounting and Reporting by Charities: Statement of Recommended Practice for Charities, (www.charitysorp.org).

Connolly, C. and A. Dhanani (2009), Research Report 109: Narrative Reporting by UK Charities, Association of Chartered Certified Accountants (London).

Connolly, C. and N. Hyndman (2013a), 'Charity Accountability in the UK: Through the Eyes of the Donor', Qualitative Research in Accounting and Management, Vol. 10, No. 3/4, pp. 259278.

(2013b), 'Towards Charity Accountability: Narrowing the Gap Between Provision and Needs?', Public Management Review, Vol. 15, No. 1, pp. 1-24.

Dhanani, A. and C. Connolly (2012), 'Discharging Not-for-profit Accountability: UK Charities and Public Discourse', Accounting, Auditing and Accountability Journal, Vol. 25, No. 7, pp. 1140-1169.

Donaldson, T. and L.E. Preston (1995), 'The Stakeholder Theory of the Corporation: Concepts, Evidence, and Implications', Academy of Management Review, Vol. 20, No. 1, pp. 65-91.

Ebrahim, A. (2003), 'Accountability in Practice: Mechanisms for NGOs', World Development, Vol. 31, No. 5, pp. 813-829.

Etzioni, A. (2010), 'Is Transparency the Best Disinfectant?', Journal of Political Philosophy, Vol. 18, No. 4, pp. 389-404.

Freeman, R.E. (1984), Strategic Management: A Stakeholder Approach (Pitman, Boston).

Gamble, A. (2008), Benchmarking in the Third Sector, (www.ces-vol.org.uk).

Heald, D. (2006a), 'Varieties of Transparency', in C. Hood and D. Heald (eds.), Transparency: The Key to Better Governance? Proceedings of the British Academy 135 (Oxford University Press, Oxford). 
(2006b), Transparency as an Instrumental Value', in C. Hood and D. Heald (eds.), Transparency: The Key to Better Governance? Proceedings of the British Academy 135 (Oxford University Press, Oxford).

Hedley, S., S. Keen, T. Lumley, E. Ní Ógáin, J. Thomas and M. Williams (2010), Talking About Results, New Philanthropy Capital (London).

HM Treasury (2014), The Green Book: Appraisal and Evaluation in Central Government, (www.gov.uk).

Hyndman, N. (1990), 'Charity Accounting: An Empirical Study of the Information Needs of Contributors to UK Fundraising Charities', Financial Accountability and Management, Vol. 6, No. 4, pp. 295-307.

Hyndman, N. and D. McConville (2016), 'Transparency in Reporting on Charity Efficiency: A Stakeholder Perspective', Nonprofit and Voluntary Sector Quarterly, Vol. 45, No. 4, pp. 844-865.

Inspiring Impact (2013), The Code of Good Impact Practice, (www.inspiringimpact.org).

Krippendorff, K. (2013), Content Analysis: An Introduction to its Methodology, 3rd edn. (Sage, California).

Lumley, T., B. Rickey and M. Pike (2011), Inspiring Impact: Working Together for a Bigger Impact in the UK Social Sector, (www.thinknpc.org).

McDowell, E.A., W. Li and P.C. Smith. (2013), 'An Experimental Investigation of US Individual Donors' Information Needs and Use', Financial Accountability \& Management, Vol. 29, No. 3, pp. 327-347.

Murray, P., G. Hoare and S. Wixley (2016), Boldness in Times of Change, (www.thinknpc.org).

National Council for Voluntary Organisations (NCVO) (2011), Measuring Impact - A Guide to Resources, (www.ncvo-vol.org.uk).

------ (2014), NCVO UK Civil Society Almanac 2014, (http://data.ncvo.org.uk/).

Nevill, C. and T. Lumley (2011), Measuring Together: Impact Measurement in the Youth Justice Sector, (www.thinknpc.org).

O'Neill, O. (2006), 'Transparency and the Ethics of Communication', in C. Hood and D. Heald (eds.), Transparency: The Key to Better Governance? Proceedings of the British Academy 135 (Oxford University Press, Oxford).

Populus (2016), Public Trust and Confidence in Charities: Research Conducted by Populus on Behalf of the Charity Commission, (www.gov.uk).

Puttick, R. and J. Ludlow (2012), Standards of Evidence for Impact Investing, (www.nesta.org.uk).

Ryan, C., J. Mack, S. Tooley and H. Irvine (2014), 'Do Not-for-Profits Need Their Own Conceptual Framework?', Financial Accountability \& Management, Vol. 30, No. 4, pp. 383402.

Saxton, G.D., J.S. Kuo, and Y.C. Ho (2012), 'The Determinants of Voluntary Financial Disclosure by Nonprofit Organizations', Nonprofit and Voluntary Sector Quarterly, Vol. 41, No. 6, pp. 1051-1071.

Schreier, M. (2012), Qualitative Content Analysis in Practice (Sage, London). 
Table 1: A stakeholder-focused framework of transparent reporting on effectiveness

\begin{tabular}{|c|c|}
\hline Framework items & Explanation, example, advocates ${ }^{\text {xvi }}$ \\
\hline \multicolumn{2}{|l|}{ Measures } \\
\hline Output & $\begin{array}{l}\text { The immediate, or direct, products or services of the charity, for example: } \\
\text { ' } 650 \text { children were fed'. See Charity Commission (2004); Charity } \\
\text { Commission and OSCR (2014). }\end{array}$ \\
\hline Individual outcome & $\begin{array}{l}\text { The long-term effect on individuals, for example: '63\% of participants found } \\
\text { employment'. See Charity Commission and OSCR (2014). }\end{array}$ \\
\hline Societal outcome & $\begin{array}{l}\text { The long-term effect on society, for example: 'reoffending in the area } \\
\text { decreased to } 22 \% \text { '. See Charity Commission and OSCR (2014). }\end{array}$ \\
\hline Output-based effectiveness & $\begin{array}{l}\text { A comparison between an output and a specific, pre-set target, for example: } \\
\text { ' } 840 \text { inoculations, against target of 900'. See Connolly and Dhanani (2009); } \\
\text { Breckell et al. (2011). }\end{array}$ \\
\hline Outcome-based effectiveness & $\begin{array}{l}\text { A comparison between an (individual or societal) outcome and a specific, } \\
\text { pre-set target, for example: 'reoffending at 10\%, against our target of } 15 \% \text { '. } \\
\text { See Connolly and Dhanani (2009); Breckell et al. (2011). }\end{array}$ \\
\hline \multicolumn{2}{|r|}{ 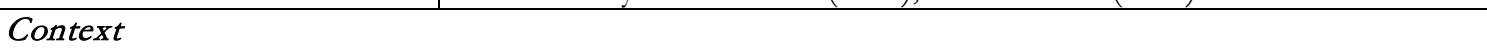 } \\
\hline Explanation & $\begin{array}{l}\text { Explanation and/or additional contextual information, for example: 'our } \\
\text { success rate was } 76 \% \text {. This means that... a factor influencing that...'. See } \\
\text { Hedley et al. (2010); Inspiring Impact, (2013). }\end{array}$ \\
\hline Prior-year comparatives & $\begin{array}{l}\text { Comparison to same measure in the previous year, for example: 'this } \\
\text { decreased from } 720 \text { children fed last year'. See NCVO (2011); Charity } \\
\text { Commission and OSCR (2014). }\end{array}$ \\
\hline External comparatives & $\begin{array}{l}\text { Comparison to an external target or organisation, for example: 'charity X } \\
\text { reported a } 54 \% \text { employment rate'. See Gamble (2008); Nevill and Lumley } \\
\text { (2011). }\end{array}$ \\
\hline Link to overall mission & $\begin{array}{l}\text { Clear link from measure to charity mission or long-term goals, for example: } \\
\text { ‘ } 67 \% \text { were more confident: a step towards employability, our long-term } \\
\text { goal'. See NCVO (2011). }\end{array}$ \\
\hline \multicolumn{2}{|l|}{ Format } \\
\hline Numerical & $\begin{array}{l}\text { A quantitative or monetary measure, for example: 'we fed } 412,000 \text { children' } \\
\text { or 'the estimated benefit was } £, 10 \text { million'. See Hedley et al. (2010); NCVO } \\
\text { (2011). }\end{array}$ \\
\hline Narrative & $\begin{array}{l}\text { Use of narrative without a numerical measure, for example: 'we provided } \\
\text { feeding programmes in Region X'. See Connolly and Dhanani (2009); } \\
\text { Hedley et al. (2010). }\end{array}$ \\
\hline Case-study & $\begin{array}{l}\text { Case studies identify effects on specific individuals or communities, for } \\
\text { example: 'We helped Ethel by...'. See Hedley et al. (2010); Inspiring Impact } \\
\text { (2013). }\end{array}$ \\
\hline \multicolumn{2}{|l|}{ Reliability } \\
\hline $\begin{array}{l}\text { Method used to } \\
\text { gather/calculate }\end{array}$ & $\begin{array}{l}\text { Evidence on how information was gathered or calculated, for example: 'we } \\
\text { asked a random sample of } 400 \text { beneficiaries to complete a questionnaire... } \\
\text { We received } 70 \text { responses and found that.... See Charity Commission } \\
\text { (2004); Puttick and Ludlow (2012). }\end{array}$ \\
\hline Reference to external sources & $\begin{array}{l}\text { Reference to external sources, for example: 'we based our estimate of value } \\
\text { added on the indicators developed by X...'. See Puttick and Ludlow (2012). }\end{array}$ \\
\hline $\begin{array}{l}\text { Evidence of independent } \\
\text { preparation or verification }\end{array}$ & $\begin{array}{l}\text { Information on external, independent preparers or evaluators, for example: } \\
\text { 'this measure has been prepared/verified by XYZ ...'. See Puttick and } \\
\text { Ludlow (2012); Connolly and Hyndman (2013b). }\end{array}$ \\
\hline Examples of 'bad news' & $\begin{array}{l}\text { Examples of poor performance, project failures, negative effects or missed } \\
\text { targets, for example: 'we expected to place } 70 \text { volunteers this year but placed } \\
\text { 65...' See Dhanani and Connolly (2012); Inspiring Impact (2013). }\end{array}$ \\
\hline \multicolumn{2}{|l|}{ Causality } \\
\hline $\begin{array}{l}\text { Extent of change caused by } \\
\text { charity }\end{array}$ & $\begin{array}{l}\text { Comment on the extent to which the charity can claim credit for the change } \\
\text { reported, for example: ' } 80 \% \text { of participants believed that without us they } \\
\text { would not have gained the qualification'. See Inspiring Impact (2013). }\end{array}$ \\
\hline
\end{tabular}




\begin{tabular}{|l|l|}
\hline $\begin{array}{l}\text { Evidence of what might have } \\
\text { happened without } \\
\text { intervention }\end{array}$ & $\begin{array}{l}\text { Reference to a comparable situation or control group, for example: 'the } \\
\text { recovery rate was 25\%, compared to an average of 16\%...'. See Nevill and } \\
\text { Lumley (2011); Puttick and Ludlow (2012). }\end{array}$ \\
\hline $\begin{array}{l}\text { Other factors/organisations } \\
\text { impacting on change }\end{array}$ & $\begin{array}{l}\text { Information on other factors/organisations' impact on change reported, for } \\
\text { example: 'participants are also required to undertake the XYZ scheme'. See } \\
\text { Nevill and Lumley (2011); Inspiring Impact (2013). }\end{array}$ \\
\hline Stakeholder involvement \\
\hline $\begin{array}{l}\text { Evidence of stakeholder } \\
\text { consultation in design of } \\
\text { measures }\end{array}$ & $\begin{array}{l}\text { Information on stakeholder consultation in designing measures, for example: } \\
\text { 'our beneficiaries see employment rates as a key measure of success'. See } \\
\text { NCVO (2011). }\end{array}$ \\
\hline $\begin{array}{l}\text { Evidence of stakeholder } \\
\text { involvement in measuring } \\
\text { performance }\end{array}$ & $\begin{array}{l}\text { Evidence of stakeholder involvement in assessing performance, for example: } \\
\text { '73\% of beneficiaries surveyed felt that the course improved their } \\
\text { confidence'. See Benjamin (2012); Inspiring Impact (2013). }\end{array}$ \\
\hline
\end{tabular}


Table 2: Proportion of charities reporting framework measures

\begin{tabular}{|c|c|c|c|c|c|c|c|c|}
\hline \multirow[t]{2}{*}{$\begin{array}{l}\text { Framework } \\
\text { measures } \\
(\text { Table 1) } \\
\end{array}$} & \multicolumn{2}{|c|}{$\begin{array}{c}\text { Any } \\
\text { communication } \\
(n=100)\end{array}$} & \multicolumn{2}{|c|}{$\operatorname{TAR}(n=100)$} & \multicolumn{2}{|c|}{$\begin{array}{c}\text { Annual Review } \\
\qquad(n=63)\end{array}$} & \multicolumn{2}{|c|}{$\begin{array}{l}\text { Website content } \\
\qquad(\mathrm{n}=99)\end{array}$} \\
\hline & No. & $\%$ & No. & $\%$ & No. & $\%$ & No. & $\%$ \\
\hline Output & 99 & $99 \%$ & 93 & $93 \%$ & 59 & $94 \%$ & 69 & $70 \%$ \\
\hline Individual outcome & 90 & $90 \%$ & 65 & $65 \%$ & 53 & $84 \%$ & 61 & $62 \%$ \\
\hline Societal outcome & 64 & $64 \%$ & 50 & $50 \%$ & 42 & $67 \%$ & 21 & $21 \%$ \\
\hline $\begin{array}{l}\text { Output-based } \\
\text { effectiveness }\end{array}$ & 42 & $42 \%$ & 40 & $40 \%$ & 10 & $16 \%$ & 1 & $1 \%$ \\
\hline $\begin{array}{l}\text { Outcome-based } \\
\text { effectiveness }\end{array}$ & 26 & $26 \%$ & 21 & $21 \%$ & 7 & $11 \%$ & 1 & $1 \%$ \\
\hline $\begin{array}{l}\text { Reporting at least } \\
\text { one of these }\end{array}$ & 100 & $100 \%$ & 97 & $97 \%$ & 63 & $100 \%$ & 87 & $88 \%$ \\
\hline
\end{tabular}


Table 3: Extent of reporting of framework measures

\begin{tabular}{|c|c|c|c|c|c|c|c|c|c|c|c|c|}
\hline \multirow{2}{*}{$\begin{array}{l}\text { Framework } \\
\text { measures } \\
\text { (Table 1) }\end{array}$} & \multicolumn{4}{|c|}{ TAR $(n=100)$} & \multicolumn{4}{|c|}{ Annual Review $(n=63)$} & \multicolumn{4}{|c|}{ Website $(n=99)$} \\
\hline & $\dot{\mathbf{Z}}$ & $\stackrel{\dot{0}}{H}$ & $\sum^{\mathbb{E}}$ & $\sum_{i}^{\dot{x}}$ & $\dot{\mathrm{Z}}$ & $\stackrel{\dot{0}}{H}$ & $\sum_{\Sigma}^{\tilde{J}}$ & $\sum_{\dot{z}}^{\dot{x}}$ & $\dot{\mathrm{Z}}$ & $\stackrel{\dot{0}}{H}$ & $\sum_{\tilde{J}}^{\mathbb{E}}$ & 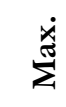 \\
\hline Output & 93 & 3661 & 39.37 & 183 & 59 & 3088 & 52.34 & 449 & 69 & 2073 & 30.04 & 376 \\
\hline $\begin{array}{l}\text { Individual } \\
\text { outcome }\end{array}$ & 65 & 570 & 8.77 & 65 & 53 & 995 & 18.77 & 128 & 61 & 2508 & 41.11 & 303 \\
\hline $\begin{array}{l}\text { Societal } \\
\text { outcome }\end{array}$ & 50 & 288 & 5.76 & 27 & 42 & 551 & 13.12 & 95 & 21 & 180 & 8.57 & 52 \\
\hline $\begin{array}{l}\text { Output-based } \\
\text { effectiveness }\end{array}$ & 40 & 552 & 13.80 & 54 & 10 & 110 & 11.00 & 39 & 1 & 0 & 0.00 & 0 \\
\hline $\begin{array}{l}\text { Outcome- } \\
\text { based } \\
\text { effectiveness }\end{array}$ & 21 & 173 & 8.24 & 72 & 7 & 52 & 7.43 & 31 & 1 & 7 & 7.00 & 7 \\
\hline
\end{tabular}


Table 4: Provision of comparatives, explanations and format

\begin{tabular}{|l|c|c|c|c|c|}
\hline $\begin{array}{l}\text { Framework elements } \\
\text { (Table 1) }\end{array}$ & Output & $\begin{array}{c}\text { Individual } \\
\text { outcome }\end{array}$ & $\begin{array}{c}\text { Societal } \\
\text { outcome }\end{array}$ & $\begin{array}{c}\text { Output-based } \\
\text { effectiveness }\end{array}$ & $\begin{array}{c}\text { Outcome- } \\
\text { based } \\
\text { effectiveness }\end{array}$ \\
\hline Number reported & 8822 & 4073 & 1019 & 663 & 232 \\
\hline $\begin{array}{l}\text { Prior-year } \\
\text { comparatives }\end{array}$ & $8 \%$ & $9 \%$ & $2 \%$ & $16 \%$ & $9 \%$ \\
\hline External comparatives & $0 \%$ & $0 \%$ & $0 \%$ & $0 \%$ & $0 \%$ \\
\hline Explanations & $13 \%$ & $6 \%$ & $21 \%$ & $28 \%$ & $33 \%$ \\
\hline Format & $72 \%$ & $27 \%$ & $38 \%$ & $65 \%$ & $39 \%$ \\
\hline Numerical & $28 \%$ & $12 \%$ & $56 \%$ & $35 \%$ & $39 \%$ \\
\hline Narrative & $0 \%$ & $61 \%$ & $6 \%$ & $0 \%$ & $22 \%$ \\
\hline Case study & & & & \\
\hline
\end{tabular}


Table 5: Provision of links to mission and information indicating reliability, causality and stakeholder involvement

\begin{tabular}{|c|c|c|c|c|c|}
\hline Framework elements (Table 1) & $0 \%$ & $1-20 \%$ & $\begin{array}{c}21- \\
50 \%\end{array}$ & $\begin{array}{c}51- \\
99 \%\end{array}$ & $100 \%$ \\
\hline Links to overall mission or long-term goals & $29 \%$ & $19 \%$ & $29 \%$ & $17 \%$ & $6 \%$ \\
\hline \multicolumn{6}{|l|}{ Reliability } \\
\hline Method used to gather/calculate & $92 \%$ & $3 \%$ & $3 \%$ & $1 \%$ & $1 \%$ \\
\hline Reference to external sources & $90 \%$ & $5 \%$ & $2 \%$ & $3 \%$ & $0 \%$ \\
\hline Evidence of independent preparation or verification & $89 \%$ & $7 \%$ & $1 \%$ & $2 \%$ & $1 \%$ \\
\hline Examples of 'bad news' & $66 \%$ & $30 \%$ & $4 \%$ & $0 \%$ & $0 \%$ \\
\hline \multicolumn{6}{|l|}{ Causality } \\
\hline Extent of change caused by charity & $83 \%$ & $12 \%$ & $4 \%$ & $1 \%$ & $0 \%$ \\
\hline $\begin{array}{l}\text { Evidence of what might have happened without } \\
\text { intervention }\end{array}$ & $93 \%$ & $3 \%$ & $3 \%$ & $1 \%$ & $0 \%$ \\
\hline Other factors/organisations impacting on change & $59 \%$ & $30 \%$ & $10 \%$ & $1 \%$ & $0 \%$ \\
\hline \multicolumn{6}{|l|}{ Stakeholder involvement } \\
\hline Evidence of stakeholder consultation in design of measures & $96 \%$ & $2 \%$ & $2 \%$ & $0 \%$ & $0 \%$ \\
\hline $\begin{array}{l}\text { Evidence of stakeholder involvement in measuring } \\
\text { performance }\end{array}$ & $66 \%$ & $23 \%$ & $7 \%$ & $3 \%$ & $1 \%$ \\
\hline
\end{tabular}




\section{ENDNOTES}

${ }^{i}$ In addition, there are many exempt charities (mostly universities, educational institutions and national museums) and excepted charities (including religious charities), which are not required to register with one of the various jurisdictional UK charity regulators.

ii A range of terms and definitions are used in practice, including 'outcomes', 'results' and 'impact' which have similar meanings. The term 'outcomes' is used throughout this paper for convenience.

iii SORPs are recommendations on accounting practice for specialised industries or sectors, and they supplement other legal and regulatory requirements. Large UK charities (including those in this study) must comply with the Charity SORP. The SORP requires charities to prepare, among other things, a Trustees' Annual Report (TAR), and, within this, reporting on achievements is necessary.

iv While the current SORP (Charity Commission and OSCR, 2014) was not yet in force at the time of this research, new recommendations are generally well publicised through consultations and the sector would have been aware of this coming change.

v NCVO (2014) estimates that over one-third of the total income of UK charities is derived from statutory sources, with the vast majority ( 80 per cent) of this provided on the basis of contracts for services.

vi Issues relating to efficiency, cost control and economy may also be important in gaining a holistic view of organisational effectiveness, and are examined by the authors elsewhere (Hyndman and McConville, 2016).

vii For example, tools such as Social Return on Investment (SROI) had not yet influenced reporting practice at the time of this research and were excluded.

viii Such charities are subject to a much narrower group of stakeholders and, given that they do not directly provide charitable services, their reporting of performance is likely to be significantly different.

ix Variations in reporting practices relating to income and cause were identified, but given the focus of this paper (on understanding a breadth of reporting practices) and length considerations, these are not discussed here.

$x$ As non-statutory documents, charities used a range of titles for such voluntary communications. However, in this paper, any similar document was referred to as an Annual Review.

xi The same approach was also used in Table 3.

xii For example, on their websites, a number of large overseas-aid charities provided outcome case studies from each country in which they operated (by type of activity). This resulted in numerous cases of individual outcome.

xiii In total 14,809 measures were analysed - 8,822 outputs, 4,073 individual outcomes, 1,091 societal outcomes, 663 outcome-based effectiveness measures, 232 outcome-based effectiveness measures.

xiv This is not considered as a measure of effectiveness in this paper (the definition in Table 1 requires a comparison to a specific, pre-set target).

$\mathrm{xv}$ This list was updated annually, and it is not possible to view previous lists online.

xviA more detailed framework with rationale for the inclusion of each item is available from the authors on request.

xvii This is more difficult where beneficiaries cannot be engaged either because of their nature (wildlife charities), urgency of need (disaster relief charities) or remoteness from charitable activities (medical research charities). 